\title{
Biosecurity Practices Applied in Aquacultural Farms in Northern Senegal, West Africa
}

\author{
Robane Faye, \\ Department of Aquaculture, Aquatic Animals Health, \\ Faculty of Agronomic Sciences, Aquaculture and Food Technologies, \\ Gaston Berger University, Route de Ngallèle Saint-Louis, Sénégal \\ Nicolas Djighnoum Diouf, \\ Department of Animal Husbandry and Livestock, Animal Health and \\ Feeding, Faculty of Agronomic Sciences, Aquaculture and Food \\ Technologies, Gaston Berger University, Route de Ngallèle Saint-Louis, \\ Sénégal \\ Mouhamadou Amadou LY, \\ Department of Aquaculture, Aquatic Animals Food and Feeding, \\ Faculty of Agronomic Sciences, Aquaculture and Food Technologies, \\ Gaston Berger University, Route de Ngallèle BP 234 Saint-Louis, Sénégal \\ Justin Ayayi Ayih-Akakpo, \\ Department of Microbiology-Immunology, Infectious Diseases, \\ Inter-State School of Veterinary Sciences and Medicine of Dakar, \\ Avenue Cheikh Anta Diop Dakar Fann, Senegal
}

\begin{abstract}
This study was conducted in northern Senegal, covering the regions of Saint-Louis, Louga and Matam, from June 2016 to December 2016. Surveys were carried out at all farms in this area where fish, shrimp, and molluscs farming or grow-out activities are conducted. The sampling method used is the survey determined by respondents which is a variation of snowball sampling. This method allowed us to administer a questionnaire to the fiftynine farms in activity in northern Senegal. The overall objective of this paper is to contribute to the improvement of knowledge on aquaculture biosecurity in the study areas through the application of biosecurity measures. This study highlighted the interconnections between the different farms, identified biosecurity measures for infrastructure, livestock and food, and assessed the different biosecurity measures applied to staff. The results revealed that biosecurity measures are poorly implemented. $74.6 \%$ of the people surveyed are also unaware of the mechanisms by which aquatic animal diseases appear and spread out, while $86.4 \%$ of them have no knowledge of biosecurity in
\end{abstract}


aquaculture. Our recommendations focus on the need to encourage aquaculture professionals to apply biosecurity measures at all production stages. There is also the need for training or capacity building for aquaculture farmers on biosecurity measures.

Keywords: Aquaculture, Biosecurity Measures, Northern Zone, Senegal

\section{Introduction}

World aquaculture production has been increasing steadily at an impressive annual rate of about 11\% since 1980 (Lee, 2005). In aquaculture, pathogens tend to cause infections when a host/pathogen imbalance occurs. This leads to a deterioration of the aquatic environment to such an extent that the natural resistance of farmed aquatics animals is compromised and the infection progresses to disease. Good management practices can help maintain this host/pathogen balance, thus minimizing disease occurrence (Plumb, 2002). Viral infections of shrimp farming epidemics have caused billions of dollars in lost income (Lightner, 2003). The best way to control disease outbreaks in aquaculture is through prevention, and this requires the application of biosecurity measures. Biosecurity in aquaculture can be defined as a set of practices, procedures, policies, and regulations used to prevent the introduction and spread of pathogenic organisms (bacteria, viruses, fungi, parasites) and many aquatic invasive species (zebra mussels, rusty crayfish) (Dvorak, 2009). Undeniably, one of the most effective and affordable ways to minimize the introduction of pathogens or invasive species on a farm is to implement a biosecurity program (FIAC, 2010). This means that biosecurity is applied at different levels. At the international level, the practice of biosecurity is mainly based on the application of national or international regulations (Codes and Standards of the World Organisation for Animal Health, the World Trade Organisation, the Codex Alimentarius). In the Aquatic Animal Health Code, clear regulatory provisions are in place to avoid the transfer of animal or human pathogens, while avoiding unjustified health barriers. Biosecurity also applies at the farm level, and the implementation of an effective biosecurity plan is essential to reduce the risk of disease introduction or spread. In aquaculture, it is better to avoid health problems than to have to deal with them. This is because economic losses are often high and is within a very short time frame. In addition, it is widely accepted that the prevention of fish diseases is less costly than their treatment (CEFAS, 2009). Despite the importance of biosecurity in livestock production and in particular in aquaculture, biosecurity plans and measures are often nonexistent or used in a reactive manner. The annual cost invested in measures to prevent outbreaks of infectious pancreatic necrosis in fish that have affected the Norwegian aquaculture industry has been estimated at about 60 million 
dollars, and this has limited the spread of the diseases in the country (FRS, 2013). It is therefore important to implement and apply good biosecurity practices in order to ensure not only productivity, but also product quality. To limit the spread of diseases in aquaculture, measures must be applied to all stakeholders, infrastructure, and the ingredients used to conduct the activity at all levels of production. Transboundary aquatic animal diseases (TADs) are caused by highly contagious pathogens that can spread very quickly, regardless of national borders, and have serious socio-economic consequences. Domestic and international trade is an important route of transmission of these diseases. Trade development, if not controlled, can lead to the emergence of new mechanisms for the introduction and spread of pathogens and diseases in new regions as their hosts move (FAO, 2010). In addition to these diseases caused by the action of microorganisms, there is a whole range of non-infectious problems caused by non-living factors (environmental, nutritional, etc.). The management of these problems require the application of strict biosecurity measures. In Senegal, aquaculture is a relatively young and undeveloped activity. However, it is a part of all economic development programs, particularly the National Strategy for Economic and Social Development (NSESD). This activity has great potential in the northern Senegal, including the regions of Saint Louis, Louga and Matam, where it is expanding rapidly with the presence of the northern branch of the National Aquaculture Agency. The open design of aquaculture sites and their water supply is a potential risk of introduction and spread out of pathogens. However, biosecurity measures can be used to reduce this risk to an acceptable level. In Senegal, aquaculture is very promising but mainly practiced in an extensive or semi-intensive level. Production yields are still low and do not yet exceed 1300 tons (FAO, 2015). This low production may be related to different parameters, including the lack of biosecurity practices. Thus, what is the level of application of biosecurity rules in aquaculture operations in northern Senegal? At farm level in the study area, biosecurity measures appear to be non-existent or insufficiently enforced. This is why we proposed to carry out this study, which focuses on the "State of implementation of biosecurity measures in aquaculture farms in the northern aquaculture zone of Senegal". The overall objective of this paper is to contribute to the improvement of knowledge on aquaculture biosecurity in northern Senegal (Saint Louis, Louga and Matam region) through the application of biosecurity measures. The specific objectives are to determine the interconnections between different farms, to identify biosecurity measures for infrastructure, livestock and food, and to evaluate the different biosecurity measures applied for by staff. 


\section{Material And Methods \\ Presentation of the Study Area}

This study was carried out in northern Senegal, covering the regions of Saint Louis, Louga and Matam, from June 2016 to December 2016. Surveys were carried out at all farms in the area where fish, shrimp, and molluscs farming or grow-out activities are conducted. Figure 1 is an illustration of the study area with the location of the different sites surveyed.

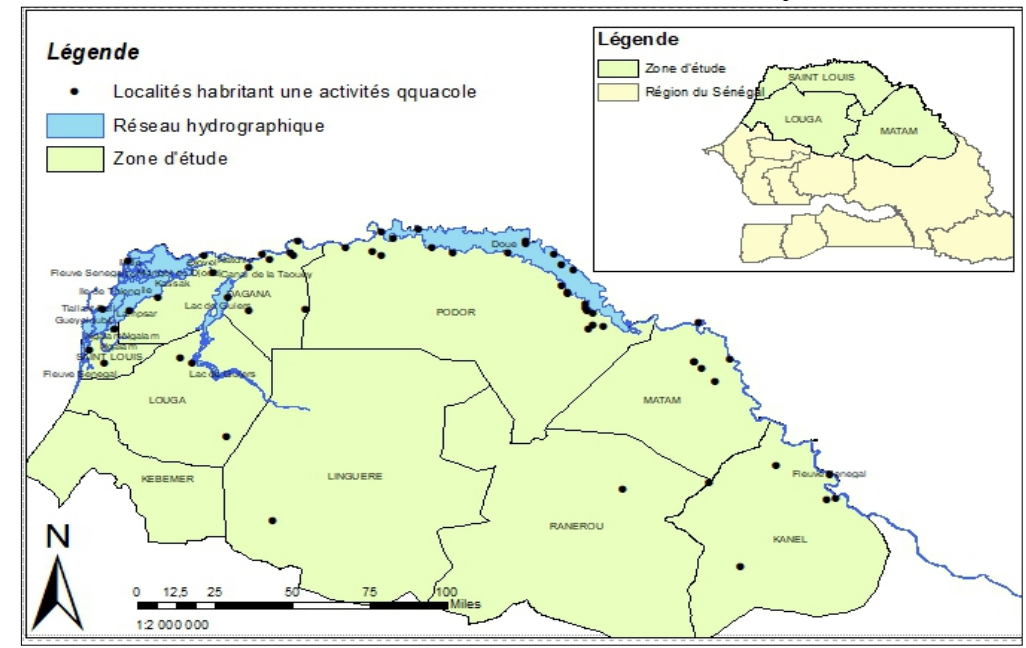

Figure 1. Geographic location of surveyed sites

\section{Material}

The material used to carry out this study consists of survey sheets that have been used to collect information on the geographical location of aquaculture farms, the relationships and interconnections between them, and the biosecurity practices applied on differents aquacultures productions systems.

\section{Sampling Methodology}

The sampling method used during this study is the survey determined by respondents. This method, which is a variation of snowball sampling, consists of selecting a farm first at random and recording all biosecurity practices. From this farm, the other farms are visited by indication of the first farm which is surveyed. Therefore, this method allowed us to administer the questionnaires to the fifty-nine farms in activity in northern Senegal.

\section{Analysis and Interpretation of the Results}

The data collection was carried out on survey forms, and the data entry was made immediately after the administration of the questionnaire. Data entry, structuring, and quality control were carried out using the Sphinx software. The data were analyzed by the $\mathrm{R}$ software once all farms were 
surveyed. The geographical location of aquaculture farms were carried out by the ArcGIS10.2.2.2 software.

\section{Results}

\section{Interconnections and Factors Favoring Contact Between the Farms in the Study}

Table 1 describes the different factors that motivate inter-farm contact. It shows that $74.6 \%[0.61 ; 0.83]$ of farms have contacts with their neighbors. $83 \%[0.71 ; 0.91]$ of farms in the same locality use the same water supply source, the Senegal river. 93.2\% [0.83;0.98] of the fish farmed in the study area come from the Aquaculture National Agency (ANA) fish farm based in Richard-Toll. The same trend is observed for the feed with a percentage of 94.9\% [0.75; 0.93] coming from ANA. Also, ANA technicians make followup visits throughout the zone. In addition, there is the presence of fish-eating birds observed at $78 \%[0.65 ; 0.87]$ of farms, which is an indirect factor of the risk of contact between farms.

Table 5. Factors motivativing inter-farm contacts

\begin{tabular}{|c|c|c|c|}
\hline Modality & Nomber of citations & $\begin{array}{l}\text { Frequency of the } \\
\text { modality }(\%)\end{array}$ & Confidence interval \\
\hline Contacts with other farms & 44 & 74,6 & {$[0.61 ; 0.83]$} \\
\hline $\begin{array}{l}\text { Using the same water } \\
\text { source (Sénégal River) }\end{array}$ & 44 & 74,6 & {$[0.61 ; 0.83]$} \\
\hline Supply of fish from ANA & 55 & 93,2 & {$[0.83 ; 0.98]$} \\
\hline $\begin{array}{l}\text { Supply of fish feed from } \\
\text { ANA }\end{array}$ & 49 & 83.0 & {$[0.71 ; 0.91]$} \\
\hline $\begin{array}{l}\text { ANA technicians follow- } \\
\text { up visits }\end{array}$ & 51 & 94,9 & {$[0.75 ; 0.93]$} \\
\hline $\begin{array}{l}\text { Presence of piscivorous } \\
\text { birds }\end{array}$ & 46 & 78.0 & {$[0.65 ; 0.87]$} \\
\hline
\end{tabular}

Consequently, the data analysis revealed an existing network (Figure 2 A) illustrating the contacts that exist between farms in northern Senegal. It can be seen that the convergence point of all the farms is either the ANA Richard Toll's fish farm or the ANA Matam's fish farm. To a lesser extent is the Maraye's fish farm of the National Agency for Agricultural Integration and Development. The grouping of farms into clusters (Figure $2 \mathrm{~B}$ ), based on existing relationships between farms, highlighted five (5) majors groups with different biosecurity practices levels. 


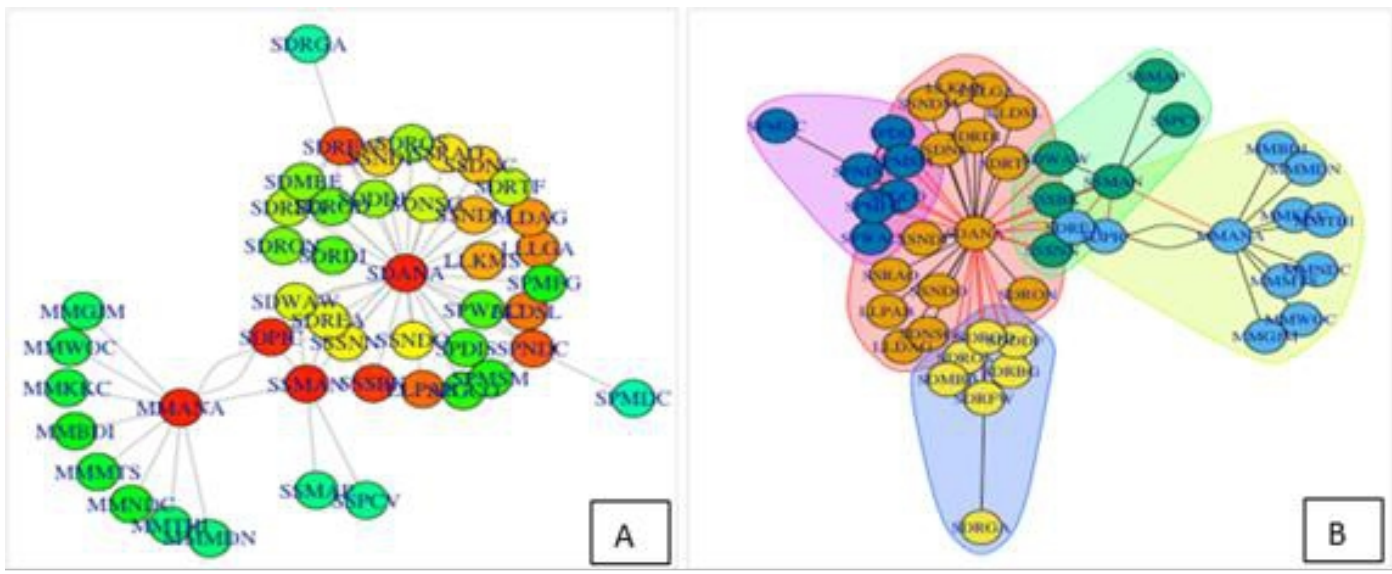

LLPAB=Ahmet Biteye Farm; LLDSL=Dierlerlou Syll Farm; LLLGA=Leona Louga Farm; LLDAG=Dagadj Farm; LLKMS=Keur Momar Sarr Farm ; SSMAN=ANIDA farm; SSNDM=Abdoulaye Mbodji Ndiarème farm ; SSDNC=Dior Ndiaye Colonats farm; SSNDI=Ndialakhar farm ;SSSBK=Balla KANE farm ; SSPCV= Shrimp Project farm ; SSRAO=RAO farm ; SSSNN=Souleye Ndiaye farm ; SSNDO=Ndombo farm ;SMAP=Maraye Private pond farm ; SDANA=Richard Toll Aquaculture national Agency farm ; SDREA=Aquaculture national Agency's hatchery; SDPIC=PIC farm ; SDWAW=Wass Walo farm ;SDNSG=Saer Gueye farm ; SDRBG=Baye Gay Rosso farm ; SDROS=Rosso farm ; SDDDF=Bonax Diack Son farm ; SOWF=Fawade Wélé farm ; SDRFW=Baye Gaye Rosso farm ; SDMBE=Mbengue farm , SDRON=Ronkh farm ; SDROD=Ousmane Diop farm ; SDRGA=Gae farm ; SDRDI=Diameguene Richard Toll farm ; SPMDC=Woury Medina Diathibé farm; SPNDC=Ndiandane farm; SPWAL=Walade Marigot;SPWAC $=$ Walade's Cage culture farm ; SPDIS=Diabo Soubalo farm; SPGCO=Gourel Comi farm; SPMSM=Soubalo Mboumba farm; SPMFG= Fondé Gandé farm; MMBDI=Belly Diallo's farm; MMANA=Matam's Aquaculture national agency farm; MMNDC=Ndouloumadji's farm; MMMTS=Thierno Samassa's farm; MMKKC=Kobilo farm; MMWOC=Woury farm; MMGJM=GIE Jeune Matam farm; MMTHI=Thiadé farm; MMMDN=NDIAYE Family's farm;

Figure 2. Network and cluster of aquaculture farms in northern Senegal

\section{Biosecurity Measures Applied to Livestock Infrastructure}

Biosecurity measures applied to infrastructures are illustrated in Figure 3. It revealed that $86.4 \%[0.47 ; 0.69]$ of infrastructures are arranged in a row while only $10.2 \%[0.25 ; 0.86]$ applies forward walking. 33.9\% [0.40;0.75] of farms are fenced, resulting to the presence of domestic animals in aquacultures farm at a frequency of $69.5 \%$ [0.46; 0.70]. It should also be noted that more than half of farms do not have bird protection, although there are fish-eating birds in the area. Disinfection of the equipments after use is respected by only $3.4 \%$ [0.08;0.97] of the farmers, while 50.8\% [0.44; 0.72] of them reported exchanging their equipments. The results also shows that the post-harvest dewatering of the pondis applied by only $15.3 \%$ [0.47;0.69] and $27.1 \%[0.38$; 0.77] perform physico-chemical analysis of the water. 


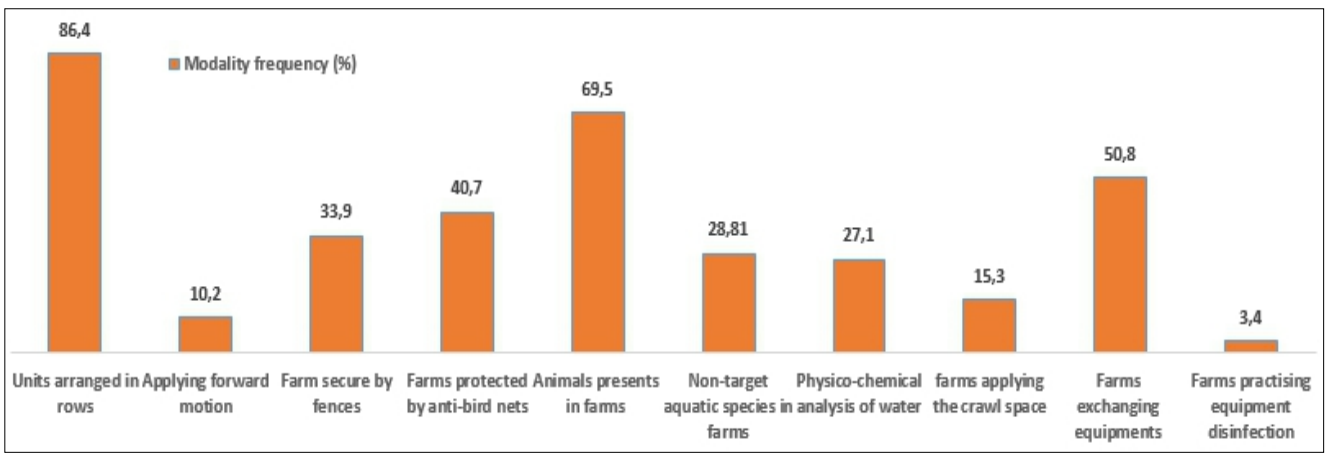

Figure 3. Biosecurity practices applied to aquaculture infrastructures

\section{Biosecurity Measures Applied to Farmed Animals}

Biosecurity measures applied to farmed animals as indicated in Figure 4 show that only $8.5 \%[0.22 ; 0.88]$ of operators keeps in quarantine aquatic animals coming from other farms. In terms of mortality management, $69.5 \%$ [0.56;0.80] of aquaculturists leave dead animals in the rearing infrastructure, while $5.1 \%[0.14 ; 0.94]$ removes and buries them. In aquaculture farms in the northern Senegal, 91.5\% [0.81;0.97] do not carry out any health treatment on farmed animals. Also, mortality rates are frequent and lesions are often observed on farmed animals. None of the farms perform microbiological analysis, only a few $(6.8 \%$ [0.19;0.91]) perform parasitological analysis and $96.6 \%$ [0.88;0.99] do not apply any biosafety instructions. Veterinary visits are received only for $15.2 \%[0.31 ; 0.82]$ of aquaculturists and $74.6 \%$ $[0.46 ; 0.70]$ of respondents have no knowledge on aquatic animal diseases.

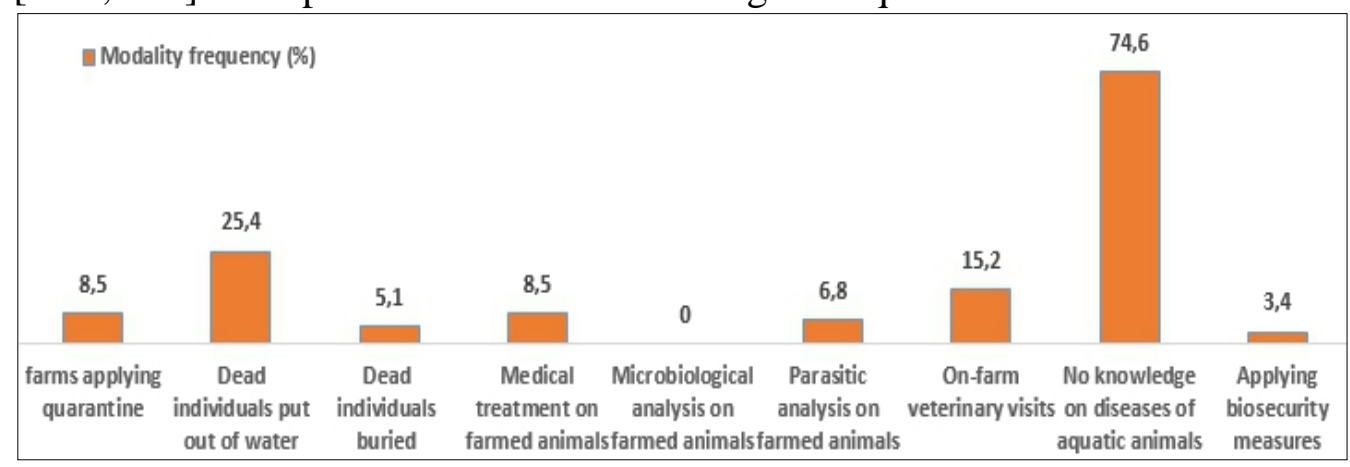

Figure 4. Biological safety measures applied to farmed animals

\section{Biosecurity Measures Applied to the Food}

The biosecurity measures applied to food are illustrated in Table 2 . The result shows that $83.1 \%$ [0.47;0.69] of farms use local food without any analysis either on the food or on the local ingredients used for its preparation. With regard to storage, it is noted that $20.3 \%$ [0.35;0.80] of farmers store their 
feed in warehouses with storage pallets, while $79.7 \%$ [0.4;0.69] of producers have their feed stored in poor conditions.

Table 2. Biosecurity measures applied to the food

\begin{tabular}{ccccc}
\hline \hline $\begin{array}{c}\text { Biosecurity } \\
\text { aspects }\end{array}$ & Modality & Citation number & Frequency (\%) & Confidence interval \\
\hline \multirow{2}{*}{ Food type } & Local & 49 & 83,1 & {$[0.47 ; 0.69]$} \\
\cline { 2 - 5 } & Industrial & 3 & 5,1 & {$[0.14 ; 0.94]$} \\
\hline & No feed & 4 & 6,8 & {$[0.19 ; 0.91]$} \\
\hline $\begin{array}{c}\text { Local food } \\
\text { ingredients } \\
\text { analysis }\end{array}$ & No Analysis & 100 & 0 & {$[0.96 ; 1.00]$} \\
\hline $\begin{array}{c}\text { Local food } \\
\text { analysis }\end{array}$ & No Analysis & 0 & 100 & {$[0.00 ; 1.00]$} \\
\hline $\begin{array}{c}\text { Food } \\
\text { storage }\end{array}$ & Analysed ingredients & 0 & 100 & {$[0.96 ; 1.00]$} \\
\cline { 2 - 5 } & Storage pallets & 12 & 0 & {$[0.00 ; 1.00]$} \\
\hline \hline
\end{tabular}

\section{Biosecurity Measures Applied by Staff and Visitors}

Figure 5 shows the frequency of application of biosecurity measures related to staff and visitors in northern Senegal fish farms. These results shows that $5.1 \%[0.14 ; 0.94]$ of the staff have work clothes, while a low percentage $(1.7 \%)[0.01 ; 0.99]$ of them pass medical examinations. It should also be noted that $61 \%$ [0.45;0.71] of the farms have no cloakroom or toilets and in none of these farms was any rotoluva or foot bath found. 98.3\% [0.91;0.99] of farms in this area receive visitors, while only $11.9 \%$ [0.28;0.85] of farms have developed visitor areas. In addition, 74.6\% [0.47;0.70] of visitors have access to water used for aquaculture, while $15.0 \%$ [0.32;0.83] of them have contact with species being raised. It should also be noted that $74.6 \%[0.47 ; 0.70]$ of the people surveyed are unaware of aquatic animal diseases, while $86.4 \%$ $[0.75 ; 0.94]$ of them have no knowledge of preventive measures applied to prevent occurrence of diseases.

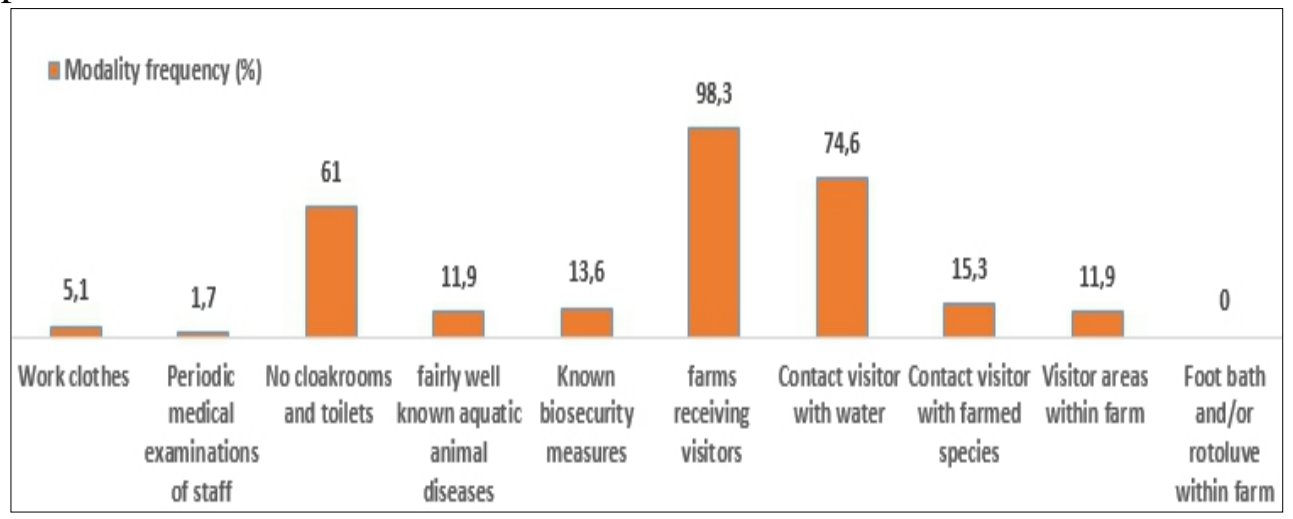

Figure 5. Application of biosecurity measures by staff and visitors 


\section{Discussion}

\section{Discussion Of The Methodology}

The sampling method determined by the respondents and used in this study consisted of the distribution of questionnaires to everyone involved in aquaculture activity in the Saint-Louis, Louga, and Matam regions. This technique allowed us to review all the aquaculture activities that are identified in northern Senegal. This method is recommended by Marpsat et al. (2010) who indicated that each time a person answers the questionnaire, they are asked to indicate one to three other people they know and who have a similar activity. Limiting the indicated persons to three has limited the biases that occur in conventional snowball sampling (Johnstona et al., 2010). This method is very well suited for studies where the target population is "difficult", low, and where there is little information. Moreover, it is a very simple method to implement when starting a new activity because such a population prevents any traditional sampling procedure, which requires databases as described by Wilhelm (2014). This situation reflects the current situation in Senegal where there is little data on aquaculture. Furthermore, the existing situation is constantly changing as new aquaculture activities are established each year throughout the country.

\section{Interconnections and Factors Favoring Farm-to-Farm Contacts in the Study}

Contacts between neighboring farms are quite frequent. Analysis of farms network and livestock clusters in the northern aquaculture zone of Senegal shows a convergence towards the fish farms of Richard-Toll and Matam and sometimes towards the farm of Maraye. These are all state-owned aquaculture management and extension structures. These farms have very strong links with others and are intermediaries between all farms. These exchanges creates biosecurity gaps. Indeed, the level of biosecurity is different depending on the clusters. On one hand, some have a relatively acceptable level of biosecurity which is the case for supervisory structures. On the other hand, others have a lower level and should be reduced to an acceptable one. When appropriate biosecurity measures are not applied, these interactions exposes all operators to the risk of the emergence and spread of health problems. However, the relationship analysis of farms shows that if such problem occurs, it will be sufficient if adequate measures are taken at the points of convergence for solution. Contacts between farms consist of good neighborly contacts and exchanges of equipments, most of which are not disinfected. In a study carried out by Koné et al. (2012), it was found that disinfection is practiced by $25.0 \%$ of the farms surveyed. This percentage of application is low, but it is better than that obtained from our study. These practices are contrary to FAO's (2012) biosecurity recommendations. Sharing 
water source without prior analysis of physical, chemical, and microbiological quality are risk factors for the spread of pathogens on farms in the study area. This risk is cross-cutting because it concerns biosecurity measures that could be applied to equipment, fish, infrastructure, and workers. Vågsholm et al. (1994) concluded in a study in Norway that the spread of salmon infectious anaemia was associated with proximity to farms that were in contact with the pathogen and at which biosecurity was poorly applied.

\section{Biosecurity Measures Applied to Equipments}

Infrastructure arrangement is necessary when considering the separation of sectors. It must be followed by the application of forward movement, which is poorly practiced in farms visited. Securing farms with fence is also important. The rarity of farm-level fencing is indeed linked to the fact that the majority of farms are located near the Senegal River. The presence of bird protection as suggested by Lotz (1979) has only been observed in a few farms that are mostly state-owned. This is also important because it prevents non-target species from gaining access to the farm. Animal bans or restrictions are measures that any fish farmer should take to prevent the emergence of possible pathogens. This is because mammals are intermediate hosts for many diseases, especially parasitic diseases to which aquatic animals are susceptible. Boutin (2001) recommended disinfecting the equipment and not exchanging it with neighbouring farms. The application of these recommendations is not observed by aquaculturists based in the northern Senegal. These practices are very similar to the study carried out by Koné et al. (2012) in Côte d'Ivoire. This study shows that $96.6 \%$ of farmers do not disinfect farm equipment after use, while more than half of farmers exchanged equipment with their neighbours. Disinfection releases material from potential pathogens (Blanco et $a l ., 2001$ ). This practice with a crawl space, only applied by $15.3 \%$ of farms, is described by Ricou (2006) as a primary prophylactic measure recommended in the management of fish farming. Studies carried out by the FRS (2005) and Raynard et al. (2007) showed that poor biosecurity enforcement poses a risk of increased occurrence and spread of pathogens and pests between farms and between farms and wild fish.

\section{Biosecurity Measures Applied to Aquatic Animals}

One of the biosecurity measures recommended in the Aquatic Animal Health Code (2017) of the OIE is the quarantine of all animals that have just arrived on a farm. This is done to assess if they are not potential vectors of pathogens, as they may be in incubation upon arrival. The practices of quarantining freshly arrived animals on the farm and the proper management of mortalities are unknown to most aquaculturists, even though they pose a risk to aquatic animals. According to Bores (2002), leaving dead aquatic 
animals in rearing infrastructure is a risk to public health and contributes to the spread of pathogens in environment. Preventive or curative treatments on farmed aquatic animals are exclusively noted for supervisory structure. This is because they are the only ones to undertake microbiological or parasitological analysis. Apart from the supervisory structures such as the National Aquaculture Agency and the National Agency for Integration and Agricultural Development, the majority of stakeholders have no knowledge of aquatic animal diseases and do not apply any biosecurity measures. As far as veterinary visits are concerned, they are received only in $15.2 \%[0.07 ; 0.26]$ of farms.

\section{Biosecurity Measures Applied to Aquatic Animals Food}

The farms surveyed use local food obtained at the management structures, while no analysis is carried out on either the food or the local inputs used for its formulation. These practices do not permit to determine the exact composition of the food, particularly in terms of essential amino acids, essential fatty acids, non-essential fatty acids, minerals, and vitamins. According to Tacon (1995), in extensive and semi-extensive farming, fish can partially meet their nutritional needs in their environment. However, when activity increases, subjects entirely depend on the complete diet provided to them throughout their farming cycle. When the formulation of the food gives an incomplete or unbalanced diet, nutritional disorders are quite frequent. The storage conditions of food are also important because they offer stability and durability. The practices noted in this study do not guarantee the quality of the food, which is most often denatured. In ingredients used to formulate fish feed, there are food products rich in polyunsaturated fatty acids (PUFAs) that are particularly affected by lipid oxidation (rancidity by oxidation). These products which include fish oils, fish meal, rice products, and oilseed meal obtained by continuous pressure have low natural antioxidant activity. In the absence of adequate antioxidant protection, lipids rich in PUFAs, including Essential Fatty Acids (EFAs), are highly exposed to auto-oxidation when in contact with atmospheric oxygen. Under these conditions, the nutritional benefit of EFAs becomes harmful to fish health (Tacon, 1995).

\section{Biosecurity Measures Applied by Staff}

One of the most common observations made is that staff at aquaculture sites, in the Saint Louis, Louga or Matam regions, rarely have work clothes. Work clothing was exclusively noted for persons in service at the supervisory structures. In addition, a large proportion of the farms surveyed do not have changing rooms, although this is very important. Some workers do not hesitate to relieve themselves in the bushes, which also exposes farms to contamination due to runoff. It is recommended that aquaculture farms should have well 
located and ready usage sanitary facilities. They must include toilet and hand washing facilities. The installation of foot baths is strongly recommended in biosecurity, especially when farms receive visitors. Visitors should not have any contact with either the farm water used for aquaculture or the animals being raised. This is because these contacts constitute a risk of the spread of zoonotic diseases. However, this is the case of Mycobacteria which are responsible for diseases in both fish and humans with Mycobacterium marinum involved in skin infections at the extremities (Richez et al., 2007). This is also the case for some vibriosis, including Vibrio parahaemolyticus, V. cholerae, V. vinifucus, and V. mimicus, which are responsible for bacterial diseases in fish but isolated from wounds, sepsis or septic arthritis in fish farmers. Contamination occurs either by ingestion or by super infected traumatic injury (Uhland et $a l ., 2000$ ). It is also possible to note the case of several parasitic diseases where humans can be either an intermediate host with nematodes like Anisakiasis or a definitive host with parasites like Diphyllobothrium spp (Roberts et al., 2012). Practices such as wearing appropriate work clothes, prohibiting all contact between people from outside the farm and aquatics animals, and switching to footbaths or rotoluva helps to limit contamination from outside. These measures recommended by Craig et al. (2006) therefore limit the spread out of pathogens in all aquaculture operations. The application of good biosecurity practices in aquaculture promotes animal welfare and productivity while ensuring better product quality and the profitability of activities.

\section{Conclusion}

This study showed that the recommendations on aquaculture biosecurity are poorly implemented in the northern Senegal (Saint-Louis, Matam and Louga). Simple practices such as quarantine, disinfection of equipments after use, storage of food in good conditions, use of work clothes for staff, management of access to the farm with a fence, visitor register, foot baths and/or a patella, and the management of injured or sick aquatics animals are poorly noted. Practices such as use of the same water source without prior physico-chemical, microbiological or parasitic analysis, exchange of equipment, and visitors' access to water and animals should be prohibited. Our recommendations highlight the need to encourage aquaculture professionals to apply biosecurity measures at all stages of production. There is also the need to train or build capacity of biosecurity aquaculture farmers.

\section{References:}

1. Blanco, M., Gibello, A. \& Fernándezgarayzábal, J.F. (2001). Influence of fish health management: Bases, procedures and economic 
implications. Departamento de Patología Animal I (Sanidad Animal), Facultad de Veterinaria. $24 \mathrm{p}$.

2. Boutin, R. (2001). La biosécurité à la ferme : un «must» pour tous les élevages ! Centre de référence en agriculture et agroalimentaire du Québec, 2875 boulevard Laurier, 22 $2^{\mathrm{e}}$ colloque sur la production porcine. $32 \mathrm{p}$.

3. Center for Environment, Fisheries and Aquaculture Science (CEFAS) (2009). Finfish Biosecurity measures plan Guidance and templates for finfish farmers and traders. Barrack Road The Nothe Weymouth Dorset DT4 8UB UK $24 \mathrm{p}$.

4. Craig, S.H., Reed, B., Keith, W., Reagan, E. \& Scott, S. (2006). Best Management Practices for Finfish Aquaculture in Massachusetts. Western Massachusetts Center for Sustainable Aquaculture. UMass Extension Publication AG-BPFA. 61 p.

5. Dvorak, G.D. (2009).Biosecurity for aquaculture facilities in the North Central Region. North Central Regional Aquaculture Center. 45 -57 p.

6. Food Agriculture Organization (FAO) (2012). Improving biosecurity through prudent and responsible use of veterinary medicines in aquatic food production, Rome, Italy.

7. Food Agriculture Organization (2010). La biosécurité aquatique: élément clé pour le développement durable de l'aquaculture. Comité des pêches. $5^{\text {e }}$ Session. Phuket Thaïlande $14 \mathrm{p}$.

8. Fisheries and Illinois Aquaculture Center (FIAC) (2010). Illinois aquaculture biosecurity manual. Prepared for Southern Illinois University Carbondale Fisheries and Illinois Aquaculture Center. 1125 Lincoln Drive Life Science II, Room 173 Carbondale, IL 62901177 p.

9. Fisheries Research Service (FRS) (2003). Final Report on the Aquaculture Health joint working Group Sub-group on infectious Pancreatic Necrosis in Scotland.; Aberdeen, Scotland; 90 p.

10. Johnstona, L.G. \& Sabinb, K. (2010). Échantillonnage déterminé selon les répondants pour les populations difficiles à joindre. Methodological Innovations 5(2) 38-48p.

11. Kibenge, F.S.B., Godoy, M.G., Fast, M., Workenhe, S. \& Kibenge, M.J.T. (2012). Countermeasures against viral diseases of farmed fish. Antiviral Research 95: 257-281p.

12. Koné, M., Cissé, M., Ouattara, M., Karamoko, Y. \& Fantodji (2012). Pratiques biosécuritaires appliquées en pisciculture dans quatre régions de Cote d'Ivoire ;Agronomie Africaine 24 (1) : 59 - 70 p.

13. Lee, C.S. (2005). Application of biosecurity in aquaculture production systems. Word Aquaculture Society. 66-75 p.

14. Lightner, D.V. (2003). Exclusion of specific pathogens for disease prevention in a penaeid shrimp biosecurity program. pp. 81-116 in: 
Lee, C.-S, and O’Bryen, P.J. (eds.) Biosecurity in Aquaculture Production Systems: Exclusion of Pathogens and Other Undesirables. The World Aquaculture Society, Baton Rouge, LA, USA.

15. Lotz, J.M. (1997). Special Topic Review: Viruses, Biosecurity and Specific Pathogen-Free Stocks in Shrimp Aquaculture. World Journal of Microbiology \& Biotechnology, vol. 13, n 4: $405-413 p$.

16. Marpsata, M. \& Razafindratsima, N. (2010). Les méthodes d'enquêtes auprès des populations difficiles à joindre : Introduction au numéro spécial ; Methodological Innovations 5(2) 3-16 p

17. OIE (2017). Code sanitaire pour les animaux aquatiques ; Vingtième édition, 340p.

18. Plumb, J.A. (2002). A Guide to the Integrated Management of Warmwater and Cool water Fish Diseases in the Great Lakes Basin; 2002.Great Lakes Fishery Commission; Project Completion Report1; Minneapolis, Minnesota .141p

19. Raynard, R., Wahli, T., Vatsos, I. \& Mortensen, S. (2007). Review of disease interactions and pathogen exchange between farmed and wild finfish and shellfish in Europe. Work package 1, deliverable 1.5. Disease interactions and pathogen exchange between farmed and wild aquatic animal populations - a European network. Issued by Veterinæmedisinsk Oppdragssenter AS. Project number: 1655. 459 p.

20. Richez, A., Lebas, D., Quinchon, J. F., Cattoen, C., Deleplancque \& Canis, F. (2007). Infection cutanée disséminée à Mycobacterium marinum chez un patient aquariophile. Institut Pasteur de Lille. 4 p.

21. Ricou, J. (2006). Guide de biosécurité. Faculté des Sciences de la Vie. EPFL-Ecublens CH- 1015 Lausanne, Suisse. 19 p.

22. Ronald, J.R. (2012). Fish Pathology; 4eme Ed Wiley Blackwell.590 p.

23. Tacon, A.G. J. (1995). Pathologie nutritionnelle des poissons. Signes morphologiques des carences et intoxications alimentaires chez les poissons d'élevage. FAO Document technique sur les pêches. No. 330. Rome, FAO. 77 p.

24. Uhland, F.C., Mikaelian, I. \& Martineau, D. (2000). Maladies des poissons d'eau douce du Québec : Guide de diagnostic ; Saint Laurent Vision 2000-466 p.

25. Vågsholm, I., Djupvik, H.O., Willumsen, FV., Tveit, AM. \& Tangen, K. (1994). Infectious salmon anaemia (ISA) epidemiology in Norway. Preventive Veterinary Medicine 19: 277-290 p.

26. Wilhelm, M. (2014). Echantillonnage boule de neige : La méthode de sondage déterminé par les répondants - Office fédéral de la statistique (OFS) Neuchâtel 60 p. 